\title{
Prolonged insulin resistance following insulin-induced hypoglycaemia
}

\author{
J. N.Clore, J. R. Brennan, S. P. Gebhart, H. H. Newsome, J. E. Nestler and W.G. Blackard \\ Departments of Medicine and Surgery, Medical College of Virginia, Richmond, Virginia, USA
}

\begin{abstract}
Summary. Nineteen normal male volunteers underwent a 10-h glucose clamp study to examine the duration and mechanism of insulin resistance after hypoglycaemia. Dextrose delivery by the Biostator to maintain the target blood glucose level fell below baseline $2 \mathrm{~h}$ after induction of hypoglycaemia and remained suppressed for at least $7 \mathrm{~h}$ after insulin hypoglycaemia. Insulin secretion as manifested by $\mathrm{C}$-peptide levels remained suppressed for 3-4 h after insulin hypoglycaemia despite return of blood glucose to baseline by $90 \mathrm{~min}$. Glucose kinetic data $\left(3-{ }^{3} \mathrm{H}\right.$-glucose) performed in six of the subjects indicated that the prolonged insulin resistance was due to significantly increased hepatic glucose production and to suppressed glucose utilisation, persisting for at least $4 \mathrm{~h}$ af-
\end{abstract}

ter counterregulatory hormone levels had returned to normal. Post-hypoglycaemic insulin resistance as determined by dextrose delivery was markedly attenuated and the rise in hepatic glucose output totally eliminated in five hypopituitary subjects without growth hormone or cortisol responses to hypoglycaemia. We conclude that post-hypoglycaemic insulin resistance occurs in non-diabetic subjects and persists for at least $7 \mathrm{~h}$ following hypoglycaemia. This prolonged insulin resistance is largely related to release of growth hormone and cortisol.

Key words: Hypoglycaemia, Somogyi phenomenon, insulin resistance, counterregulatory hormones.
In 1938 [1] and again in 1959 [2], Somogyi described a clinical phenomenon which occurs in insulin-treated diabetic patients. The Somogyi phenomenon refers to insulin resistance and rebound hyperglycaemia following insulin-induced hypoglycaemia. Insulin resistance after insulin-induced hypoglycaemia has also been observed in non-diabetic subjects [3-5]. Despite its widespread recognition as a common problem causing insulin resistance in insulin-treated patients, the excact mechanism of this phenomenon remains controversial [6-9]. The traditional explanation given for this resistance is that counterregulatory hormones secreted in response to hypoglycaemia create an insulin-resistant state $[10,11]$. Growth hormone, glucagon, epinephrine, norepinephrine, and cortisol are all capable or producing insulin resistance and their release following hypoglycaemia undoubtedly accounts for some of the insulin resistance observed. However, the counterregulatory hormone response is relatively evanescent, lasting approximately $2 \mathrm{~h}$; yet the resistance that Somogyi described is more prolonged, lasting in some cases as

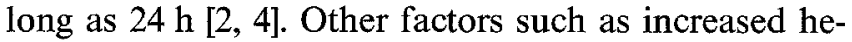
patic glucose output [12-14] and suppression of pancreatic insulin secretion $[3,15]$ have also been suggest- ed as responsible for insulin resistance after insulin-induced hypoglycaemia.

The present study was undertaken to determine the duration of insulin resistance following insulin-induced hypoglycaemia in non-diabetic subjects and to clarify the mechanisms of this resistance.

\section{Subjects and methods}

\section{Subjects}

Nineteen normal subjects (mean age $23.7 \pm 0.7$ years) volunteered for the study. Mean body mass index (BMI) was $22.7 \pm 0.5 \mathrm{~kg} / \mathrm{m}^{2}$ and all subjects had normal fasting blood glucose levels. None were on medication or had a family history of diabetes. In addition, five subjects with panhypopituitarism (mean age $47.0 \pm 7.0$ years, BMI $21.8 \pm 1.8 \mathrm{~kg} / \mathrm{m}^{2}$ ) were also studied. Two of the subjects had had non-secretory pituitary tumours, two a craniopharyngioma, and one had a history of pituitary apoplexy. All five subjects had undergone extensive testing for residual pituitary function and had been found to have absent cortisol and growth hormone responses to insulin-induced hypoglycaemia. All were on maintenance therapy including cortisol, L-thyroxine, and monthly testosterone injections.

Subjects were admitted to the Clinical Research Center of the Medical College of Virginia after an overnight fast and remained fasting until completion of the study. Written informed consent was obtained from each subject. 


\section{Experimental design}

Twelve normal subjects participated in a protocol to measure dextrose requirements during a mildly hyperglycaemic clamp (i.e., blood glucose of $5.2 \mathrm{mmol} / \mathrm{l}$ ) before and after insulin-induced hypoglycaemia. Seven subjects participated in control experiments to measure dextrose requirements during an identical mildly hyperglycaemic clamp but without insulin hypoglycaemia. In order to examine the role of growth hormone in post-hypoglycaemic insulin resistance, 5 subjects with panhypopituitarism were also studied. These subjects continued their daily thyroid replacement at a dose which had been found to normalise free T4 levels. Prior to the study, the subjects omitted their usual evening dose of cortisol replacement. In order to duplicate normal basal morning cortisol levels, an infusion of cortisol at $0.2 \mu \mathrm{g} \cdot \mathrm{kg}^{-1} \cdot \mathrm{min}^{-1}$ was initiated and continued throughout the $10-\mathrm{h}$ study.

In all 24 experiments the glucose clamp was initiated by the Biostator Glucose Controller (Life Science Instruments, Miles Laboratories, Elkhart, Ind, USA) with the appropriate software for glucose clamping. Subjects were attached to the Biostator by an intravenous catheter in each forearm, one for continuous blood withdrawal and glucose monitoring, and the other for delivery of dextrose. No insulin was infused during the clamp. Glucose monitoring was performed in non-arterialised venous blood. Although significant differences between arterial and venous plasma glucose are known to occur during periods of rapidly changing glucose levels, these differences are minimal during steady state such as existed during the preand post-hypoglycaemic periods studied [16]. The Biostator was operated in the 9:1 mode to establish a blood glucose clamp of $5.2 \mathrm{mmol} / \mathrm{l}$ via infusion of $25 \%$ dextrose at variable rates based on clamp algorithms.

In the hypoglycaemic experiments the clamp was interrupted after $3 \mathrm{~h}$ and dextrose infusions were stopped. An intravenous bolus of $0.1 \mathrm{U} / \mathrm{kg}$ of human insulin (Humulin, Eli Lilly, Indianapolis, Ind, USA) was then administered ( $0.075 \mathrm{U} / \mathrm{kg}$ for hypopituitary patients). Sixty minutes later the glucose clamp was reestablished at the same level of $5.2 \mathrm{mmol} / 1$ and maintained at this level for an additional $6 \mathrm{~h}$. In the control experiments, blood glucose was raised to $5.2 \mathrm{mmol} / 1$ and maintained at this level without interruption for insulin-induced hypoglycaemia.

Glucose appearance and disappearance rates were monitored in six of the normal subjects from the hypoglycaemic group and the five hypopituitary subjects. A primed $(22 \mu \mathrm{Ci})$ continuous $(0.22 \mu \mathrm{Ci} /$ min) infusion of $3-{ }^{3} \mathrm{H}$-glucose (New England Nuclear, Boston, Mass, USA) was begun at the initiation of the mildly hyperglycaemic clamp. The tritiated glucose was infused by a Harvard pump. After $2 \mathrm{~h}$ when equilibration had been reached, blood samples were collected every $30 \mathrm{~min}$ for assessment of glucose specific activity. Rates of glucose production and utilisation were determined during hours 3 to 10 according to the method described below using the Steele equations [17].

\section{Analytic procedures}

Blood samples were collected via a 19-guage heparin lock. $3-{ }^{3} \mathrm{H}$-glucose specific activity was determined every $30 \mathrm{~min}$, as were all other analyses. Plasma glucose was determined by the glucose oxidase method (Beckman Instruments, Fullerton, Calif, USA). Plasma insulin [18], C-peptide [19], and growth hormone [20] were determined using double antibody radioimmunoassay previously described. Cortisol was measured by direct radioimmunoassays (gamma coat assay, Clinical Assays, Cambridge, Mass, USA). Plasma glucagon was determined by a modification of the method of Aguilar-Parada and coworkers [21]. Plasma epinephrine and norepinephrine were assayed using the method of Passon and Peuler [22]. Plasma glucose radioactivity was determined in duplicate specimens at each time point. To $1.6 \mathrm{ml}$ of plasma was added $0.3 \mathrm{ml} \mathrm{3mol} / 1$ perchloric acid. After centrifugation $0.4 \mathrm{ml}$ aliquots of supernatant were air-dried and counted in a Packard $300 \mathrm{CD}$ liquid scintillation counter. Disintegrations per min were derived by an external standard method based on a quench curve. The radioactivity was found to be evenly distributed between the supernatant and sediment so the specific activity was calculated based on $1.6 \mathrm{ml}$ of plasma with correction for dilution.

\section{Calculations}

Rate of dextrose delivery was calculated as the mean value of the rates of dextrose delivery recorded each minute by the Biostator. Rates of glucose appearance ( $\mathrm{Ra}$ ) and disappearance (Rd) were calculated from the equations of Steele [17] as modified by DeBodo [24] using a pool fraction of 0.65 [25]. The rate of hepatic glucose production was then calculated as the difference between the tracer-determined rate of glucose appearance in plasma and the dextrose delivery rate.

When hepatic glucose production was suppressed during the baseline period, negative values for hepatic glucose production were observed. Rather than manipulate other variables to try to eliminate negative numbers, we have simply reported the values as calculated. Obviously, negative values are unrealistic and have led to a recent reevaluation of this procedure [23]. The large degree of negativity seen during the period of hypoglycaemia $\left(-4 \mathrm{mg} \cdot \mathrm{kg}^{-1} \cdot \mathrm{min}^{-1}\right)$ reflects the large amount of dextrose infused to return the glucose to its pretreatment level. This has also been observed by Eaton and coworkers [26] during a rigorous examination of negative numbers. In this study, large infusions of dextrose (up to $12 \mathrm{mg} \cdot \mathrm{kg}^{-1} \cdot \mathrm{min}^{-1}$ ) resulted in calculated HGO values of similar negativity. However, in the present manuscript, during the baseline and post-hypoglycaemic periods, the trend of these values has provided important information even if they do not represent absolute hepatic glucose production.

\section{Statistical analysis}

Data obtained during the third hour of the study, when a steady state had been obtained, were considered baseline for statistical purposes. Analysis of data was initially performed using Dunnett's multiple comparison test. More rigorous analysis was performed using repeated measures analysis of variance and Dunnett's multiple comparison tests. Results are expressed as mean \pm SEM.

\section{Results}

\section{Dextrose delivery before and after insulin-induced hypoglycaemia (normal subjects)}

In 12 normal subjects the amount of dextrose delivered by the Biostator during a mildly hyperglycaemic clamp was monitored both before and after insulin-induced hypoglycaemia (Fig. 1). Blood glucose rose from a fasting level of $4.3 \pm 0.07 \mathrm{mmol} / 1$ to a clamp level of $5.2 \pm$ $0.03 \mathrm{mmol} / 1$ during the initial $2 \mathrm{~h}$ equilibration period. This was accompanied by appropriate rises in insulin and C-peptide levels (Fig. 1). During the third hour of the clamp (baseline period) dextrose delivery was $3.0 \pm 0.3 \mathrm{mg} \cdot \mathrm{kg}^{-1} \cdot \mathrm{min}^{-1}$. The clamp was interrupted after the third hour and an intravenous bolus of human insulin was administered. Blood glucose levels fell to a nadir of $1.51 \pm 0.08 \mathrm{mmol} / \mathrm{l}$ after $30 \mathrm{~min}$ and then rose to $2.89 \pm 0.07 \mathrm{mmol} / 1$ after $60 \mathrm{~min}$. At this point, i. e. end of $4 \mathrm{~h}$, the clamp was re-established and dextrose delivery resumed to maintain blood glucose levels at the baseline of $5.2 \mathrm{mmol} / \mathrm{l}$ for an additional $6 \mathrm{~h}$. 

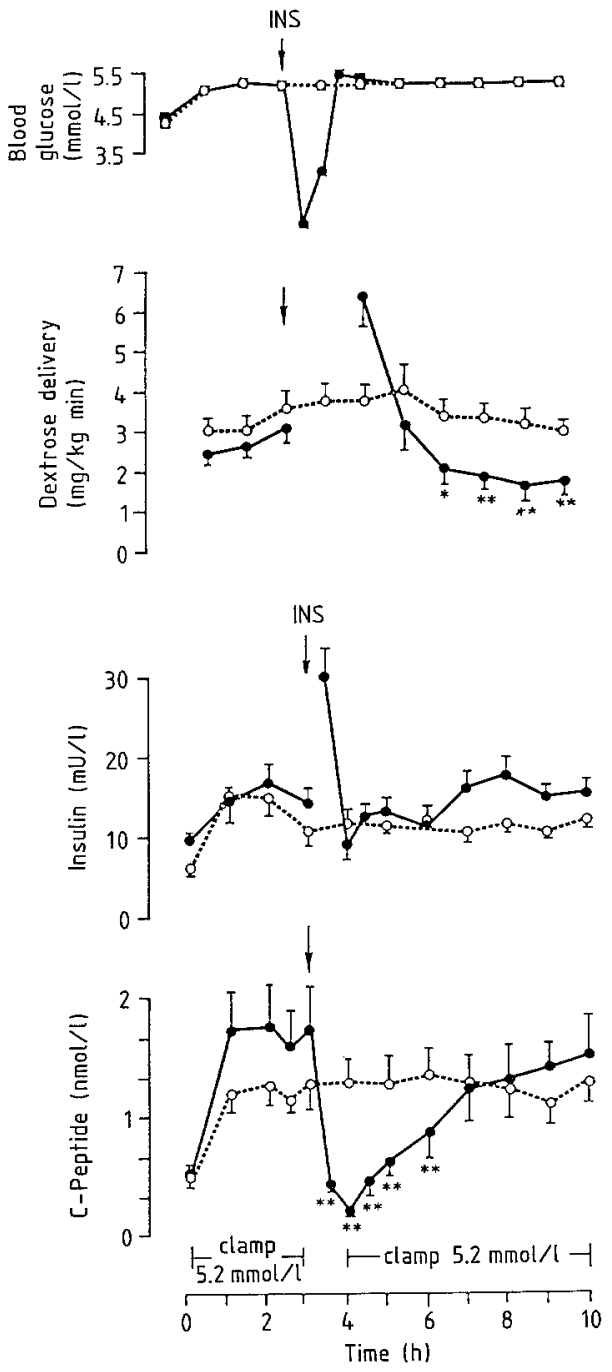

Fig. 1. Effect of insulin-induced hypoglycaemia on dextrose delivery, plasma insulin and C-peptide levels during a mildly hyperglycaemic clamp (blood glucose $5.2 \mathrm{mmol} / \mathrm{l}$ ) in 7 control $(\mathrm{O}-\mathrm{O})$ ) and 12 experimental subjects $(-0)$. In the hypoglycaemic experiments, the clamp was interrupted at $3 \mathrm{~h}$ and insulin $(0.1 \mathrm{U} / \mathrm{kg})$ was administered by intravenous bolus. The clamp was reinstituted after $60 \mathrm{~min}$. In the control experiments, the clamp remained uninterrupted. Mean \pm SEM are shown. ${ }^{*} p<0.02,{ }^{* *} p<0.01$

Dextrose delivery was initially high (5th hour) reflecting the quantity of glucose required to return the blood glucose from $2.9 \mathrm{mmol} / 1$ to $5.2 \mathrm{mmol} / 1$. Thereafter, dextrose delivery decreased to between 1.5 and $2.0 \mathrm{mg} \cdot \mathrm{kg}^{-1} \cdot \mathrm{min}^{-1}$, less than $60 \%$ of the baseline rate, and remained significantly depressed $(p<0.01)$ until completion of the study $7 \mathrm{~h}$ after insulin-induced hypoglycaemia (Fig. 1).

Blood glucose and dextrose delivery for seven subjects studied under control conditions without insulininduced hypoglycaemia are also shown in Figure 1. There was no significant decrease in dextrose delivery in control subjects, indicating that the fall in dextrose delivery seen in the hypoglycaemic subjects following hypoglycaemia was not a function of the duration of the clamp.

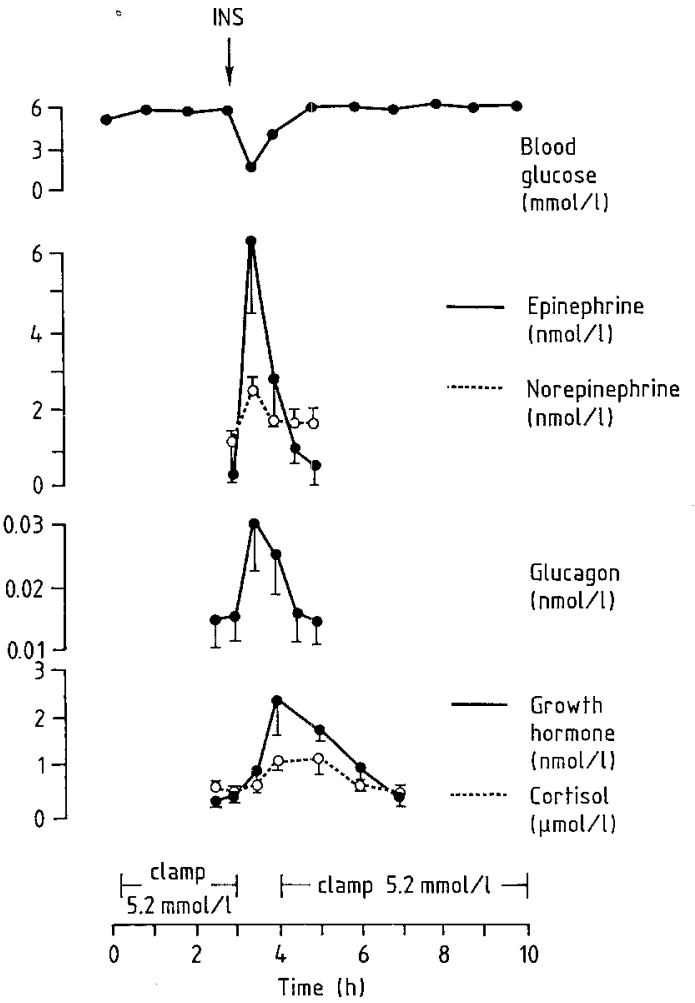

Fig. 2. Counterregulatory hormone response to insulin-induced hypoglycaemia in normal subjects $(n=12)$. Shown are plasma epinephrine, norepinephrine, glucagon, growth hormone and cortisol levels following $0.1 \mathrm{U} / \mathrm{kg}$ i.v. insulin bolus. The glucose clamp was interrupted for $60 \mathrm{~min}$ after the i.v. insulin bolus. Mean $\pm S E M$ are shown

\section{Insulin and C-peptide profile during and following insulin-induced hypoglycaemia (normal subjects)}

Plasma insulin and C-peptide levels were monitored in control subjects and in subjects exposed to hypoglycaemia (Fig. 1). The hypoglycaemia group had a fasting plasma insulin concentration of $9.3 \pm 1.2 \mathrm{mU} / 1$ which rose to $14.0 \pm 2.0 \mathrm{mU} / 1$ during the third hour (baseline period) of the mildly hyperglycaemic clamp. Following administration of the insulin bolus at $3 \mathrm{~h}$, plasma insulin levels rose precipitously and then fell to $9.0 \pm 1.6 \mathrm{mU} / 1$ at $4 \mathrm{~h}$ before slowly rising to approximately $15 \mathrm{mU} / 1$. During the last $4 \mathrm{~h}$ of the experiments when dextrose delivery was less than $60 \%$ of the baseline rate, the plasma insulin level was at least equal to, and never less than, baseline IRI. The control group had a fasting insulin concentration of $6.2 \pm 1.1 \mathrm{mU} / 1$ and maintained insulin concentrations between 10 and $15 \mathrm{mU} / \mathrm{l}$ throughout the $10 \mathrm{~h}$ clamp period.

C-peptide concentrations (Fig. 1) rose from $0.50 \pm$ $0.07 \mathrm{mmol} / 1$ to a new steady state at $1 \mathrm{~h}$, reflecting the mildly elevated glucose levels maintained during the clamp. These values remained relatively constant throughout the $10 \mathrm{~h}$ clamp period in control subjects. Following the hypoglycaemia in experimental subjects, C-peptide levels fell precipitously and remained suppressed for at least $3 \mathrm{~h}(p<0.01)$ before returning to 
baseline concentrations. Blood glucose and plasma insulin had returned to baseline by $90 \mathrm{~min}$ following hypoglycaemia.

\section{Counterregulatory hormone response to insulin-induced hypoglycaemia (normal subjects)}

The response of epinephrine, norepinephrine, glucagon, growth hormone, and cortisol to insulin-induced hypoglycaemia is shown in Figure 2. Epinephrine, norepinephrine, and glucagon reached peak levels of 6.20 , 2.57 and $0.027 \mathrm{nmol} / 1$, respectively, at $30 \mathrm{~min}$ and returned to baseline concentrations after $90 \mathrm{~min}$. Growth hormone and cortisol levels rose more slowly to peak concentrations of $2.58 \mathrm{nmol} / 1$ and $0.75 \mu \mathrm{mol} / 1$, respectively, and returned to baseline levels by $3 \mathrm{~h}$ post-insulin bolus.

\section{Glucose production and utilisation before and after insulin-induced hypoglycaemia (normal subjects)}

The fall in dextrose delivery after insulin-induced hypoglycaemia (Fig. 1) reflects a change in one or both of the components of glucose homeostasis, i.e. increased hepatic glucose production or decreased peripheral glucose utilisation. Therefore, glucose kinetics were measured in six normal subjects (Fig. 3).

Plasma glucose rose to $6.54 \pm 0.16 \mathrm{mmol} / 1$ following initiation of the clamp, fell to nadir of $1.62 \pm$ $0.09 \mathrm{mmol} / 130 \mathrm{~min}$ after the insulin bolus and had returned to $2.93 \pm 0.26 \mathrm{mmol} / 1$ at $60 \mathrm{~min}$, prior to re-establishment of the clamp. For the remainder of the study, the plasma glucose was clamped as above. As was the case with the larger number of subjects shown in Figure 1, the rate of dextrose delivery by the Biostator fell significantly to less than $50 \%$ of the baseline rate after insulin-induced hypoglycaemia $(3.26 \pm 0.24$ vs $1.68 \pm 0.20 \mathrm{mg} \cdot \mathrm{kg}^{-1} \cdot \mathrm{min}^{-1}, p<0.05$ ). Glucose utilisation (Rd) was $2.54 \pm 0.19 \mathrm{mg} \cdot \mathrm{kg}^{-1} \cdot \mathrm{min}^{-1}$ during the baseline period and transiently rose during the initial 30 min after the insulin bolus (Fig. 3). Following reinstitution of the clamp at the end of the fourth hour, $\mathrm{Rd}$ rose and then fell to a nadir of $1.96 \pm 0.13 \mathrm{mg} \cdot \mathrm{kg}^{-1}$. $\min ^{-1}$ during the final hours of study $(p<0.05)$. Hepatic glucose production was completely suppressed (negative values, see Methods) during the baseline period by the mild hyperglycaemia and elevated plasma insulin levels produced by the clamp (Fig. 3). It dramatically increased with discontinuation of dextrose infusion before falling precipitously with reinstitution of the variable dextrose delivery. Thereafter, despite re-establishment of steady state plasma glucose and insulin concentrations, hepatic glucose production was significantly increased over the baseline values and remained elevated at seventh hour after insulin-induced hypoglycaemia $(p<0.05)$.
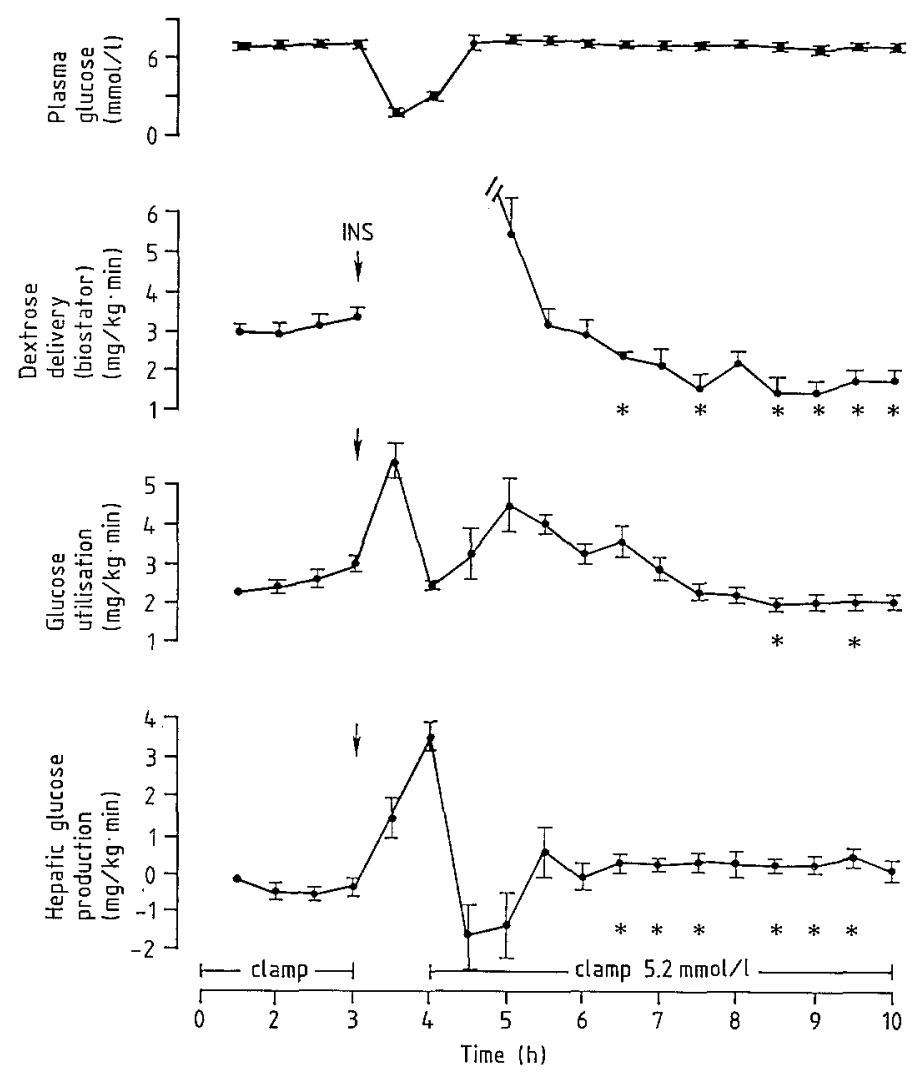

Fig. 3. Dextrose delivery by the Biostator, glucose utilisation and hepatic glucose production are shown during a mildly hyperglycaemic clamp (blood glucose $5.2 \mathrm{mmol} / \mathrm{l}$ ) in normal subjects $(n=6)$. The clamp was interrupted for $60 \mathrm{~min}$ following $0.1 \mathrm{U} / \mathrm{kg}$ i.v. insulin bolus at $3 \mathrm{~h}$. Mean $\pm \mathrm{SEM} ; * p<0.05$

\section{Studies in hypopituitary subjects}

To determine whether unsuppressed hepatic glucose production after hypoglycaemia could be attributed to pituitary factors, five panhypopituitary subjects with cortisol and thyroid replaced were studied. Dextrose delivery by the Biostator and hepatic glucose output were again examined before and after insulin-induced hypoglycaemia. Basal cortisol levels were maintained throughout by a continuous infusion of hydrocortisone (see Methods). Plasma glucose rose from fasting levels to $6.43 \pm 0.18 \mathrm{mmol} / \mathrm{l}$, fell to a nadir of less than $1.7 \mathrm{mmol} / 1$ after the insulin bolus and then returned to $6.2 \pm 0.50 \mathrm{mmol} / 1$ following re-establishment of the mildly hyperglycaemic clamp (Fig. 4). During the baseline period, dextrose delivery was $3.69 \pm 0.64 \mathrm{mg} \cdot \mathrm{kg}^{-1}$. $\mathrm{min}^{-1}$. Following hypoglycaemia, dextrose delivery again rose to return the glucose level to baseline. Thereafter, dextrose delivery fell slightly to $2.60 \pm$ $0.49 \mathrm{mg} \cdot \mathrm{kg}^{-1} \cdot \mathrm{min}^{-1}$. In contrast to the normal subjects, the suppression of dextrose delivery was minimal and did not achieve statistical significance.

Peripheral insulin levels were $20.5 \pm 7.9 \mathrm{mU} / 1$ after initiation of the mildly hyperglycaemic clamp (Fig. 5). Following administration of the insulin bolus, plasma insulin rose and then fell to $10.9 \pm 1.7 \mathrm{mU} / 1$ by $5 \mathrm{~h}$ and 

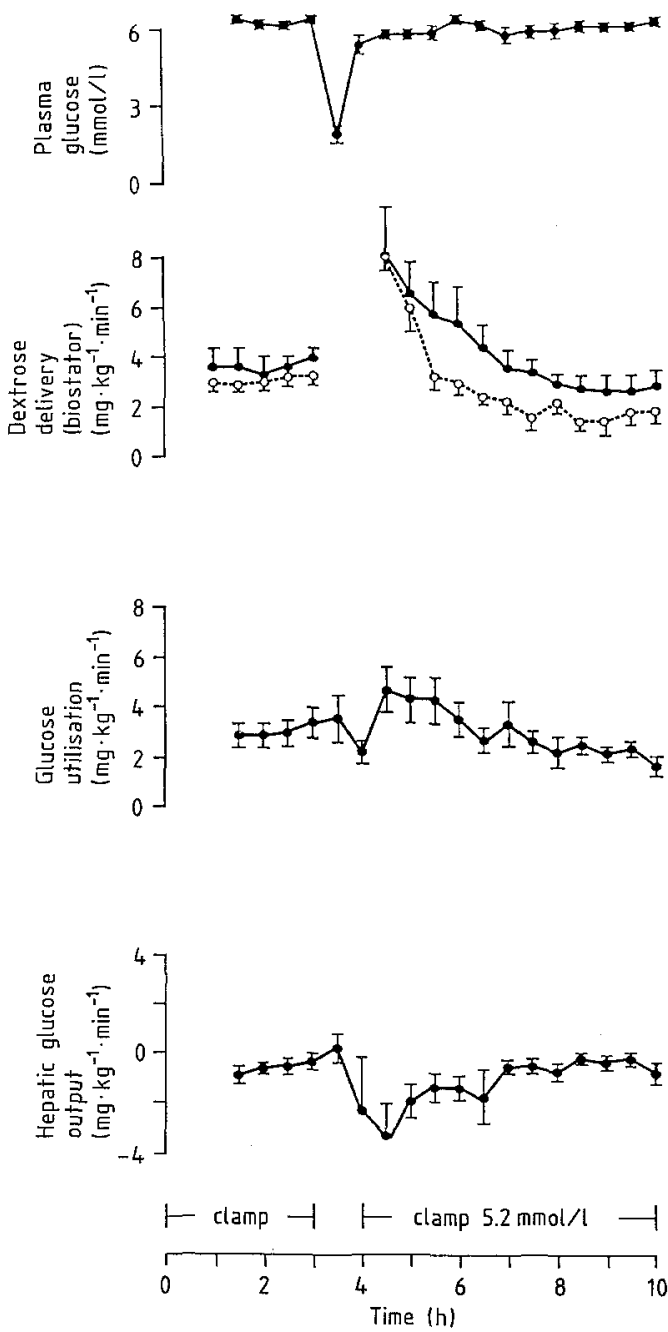

Fig.4. Plasma glucose, dextrose delivery, glucose utilisation, and hepatic glucose production are shown during a mildly hyperglycaemic clamp (blood glucose $5.2 \mathrm{mmol} / \mathrm{l}$ ) in panhypopituitary subjects $(n=5)$. Results of normal subjects are provided for comparison (O--.O). Mean \pm SEM are shown

remained somewhat lower than baseline throughout the study. However, a statistically significant fall was noted in only one of the time points. Insulin levels in the normal subjects had returned to pre-hypoglycaemic levels during the last hours of the study. C-peptide levels rose from basal levels of $0.2 \mathrm{nmol} / 1$ to $0.92 \pm$ $0.2 \mathrm{nmol} / 1$ during the baseline period and then fell to $0.46 \pm 0.24 \mathrm{nmol} / 1$ after insulin hypoglycaemia. Thereafter, C-peptide remained suppressed despite return of plasma glucose to baseline values (Fig. 5). Epinephrine, norepinephrine, and glucagon values peaked at 2.0, 2.13 and $0.04 \mathrm{nmol} / 1$, respectively, following hypoglycaemia. As expected in the growth hormone deficient subjects, peak growth hormone levels were $0.1 \mathrm{nmol} / 1$ after hypoglycaemia, in marked contrast to levels achieved in the normal subjects $(2.6 \pm 0.7 \mathrm{nmol} / \mathrm{l})$. Exogenously delivered cortisol $\left(0.2 \mu \mathrm{g} \cdot \mathrm{kg}^{-1} \cdot \mathrm{min}^{-1}\right)$ produced levels of $0.31 \pm 0.10 \mu \mathrm{mol} / 1$ throughout the study (Fig. 5).
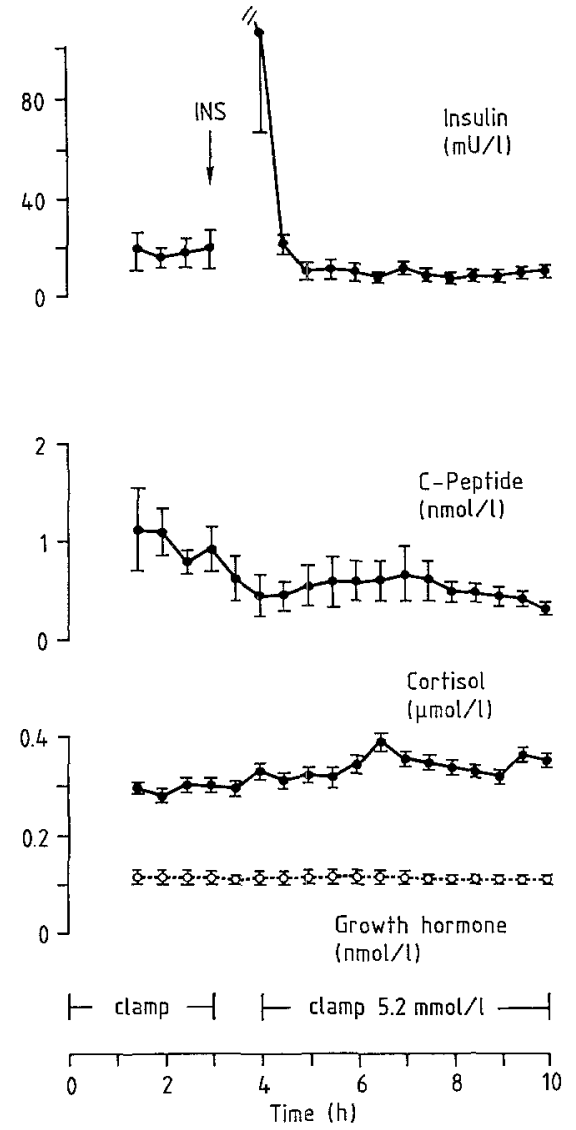

Fig.5. Plasma insulin, C-peptide, growth hormone and cortisol profiles are shown for panhypopituitary subjects $(n=5)$ during a mildly hyperglycaemic clamp (blood glucose $5.2 \mathrm{mmol} / \mathrm{l}$ ). The clamp was interrupted for an i.v. insulin bolus. Mean \pm SEM are shown

Hepatic glucose production was again suppressed during the baseline period (Fig. 5). However, in the absence of a rise in cortisol and growth hormone, hepatic glucose production failed to rise above baseline following hypoglycaemia despite prolonged suppression of insulin secretion. Glucose utilisation was $3.2 \pm$ $0.6 \mathrm{mg} \cdot \mathrm{kg}^{-1} \cdot \mathrm{min}^{-1}$ during the baseline period, and rose transiently following the insulin bolus (Fig. 4). With the re-establishment of the clamp, Rd rose and then fell slightly to levels of $2.15 \pm 0.3 \mathrm{mg} \cdot \mathrm{kg}^{-1} \cdot \mathrm{min}^{-1}$ during the last $2.5 \mathrm{~h}$ of the study.

\section{Discussion}

The Somogyi phenomenon refers to rebound hyperglycaemia and insulin resistance following insulin-induced hypoglycaemia $[1,2]$. Somogyi suggested that the resistance might last for many hours after the hypoglycaemic event. Our studies were designed to determine the duration of insulin resistance after insulin-induced hypoglycaemia in normal and hypopituitary subjects, and to clarify the mechanisms involved. Using a mildly hyperglycaemic clamp, we have demonstrated that insulin resistance, as determined by a de- 
crease in dextrose requirements, lasts at least $7 \mathrm{~h}$ following insulin-induced hypoglycaemia in normal and hypopituitary nondiabetic subjects. The effect persists for at least $4 \mathrm{~h}$ beyond the normalisation of counter-regulatory hormone concentrations. Both impaired suppression of hepatic glucose production and diminished peripheral glucose utilisation were found to contribute to post-hypoglycaemic insulin resistance in normal volunteers. Possible mechanisms which might explain the prolonged insulin resistance after hypoglycaemia include persistent effect of counterregulatory hormones [27], suppression of endogenous insulin secretion [28], and enhanced autoregulation of hepatic glucose production [29].

All of our normal subjects exhibited the classic counter-regulatory responses to insulin-induced hypoglycaemia with a rise in plasma epinephrine, norepinephrine, and glucagon during the first $30 \mathrm{~min}$ after insulin bolus, followed by a rise in plasma cortisol and growth hormone. Counterregulatory hormone levels had returned to normal by 2-3 h. In hypopituitary subjects, the counterregulatory hormone responses differed quantitatively from those of normal subjects with absent growth hormone and cortisol responses and reduced peak epinephrine levels.

For counterregulatory hormones to be responsible for prolonged post-hypoglycaemic insulin resistance, the effects of these hormones would have to persist for hours. Glucagon, which acts primarily on the liver, probably does not contribute to the effect since the duration of glucagon-induced hyperglycaemia does not persist beyond the period of hyperglucagonaemia [30]. Catecholamines, which inhibit insulin secretion via alpha-adrenergic stimulation and enhance glucose production via beta-adrenergic stimulation [31, 32], also returned to baseline levels within $90 \mathrm{~min}$ of the insulin bolus. Insulin suppression by catecholamines is rapidly reversible and should not persist after return of the hormones to baseline levels [31]. Thus, it is not surprising that previous studies have failed to show an effect of alpha-adrenergic blockade on post-hypoglycaemic insulin resistance in normal subjects [15]. On the other hand, Popp and co-workers [33] have demonstrated that in diabetic patients, beta-adrenergic blockade attenuated but did not prevent rebound hyperglycaemia after insulin-induced hypoglycaemia. A contributory effect of beta-adrenergic stimulation to the prolonged insulin resistance following insulin hypoglycaemia cannot be ruled out since studies have not been extended to determine the duration of the beta-adrenergic effect.

Somogyi favoured the hypothesis that the pituitary and adrenal anti-insulin hormones were responsible for insulin resistance occurring after hypoglycaemia [4]. Mintz and co-workers [15] emphasised the critical role of the pituitary in this phenomenon when they failed to demonstrate post-hypoglycaemic carbohydrate intolerance in patients with panhypopituitarism.
Despite the fact that acute elevations of plasma cortisol have been shown to cause hyperglycaemia by suppression of glucose uptake [34] and impaired insulin suppression of hepatic glucose output [35], the failure of metyrapine to prevent post-hypoglycaemic glucose intolerance argues against a role for cortisol in acute post-hypoglycaemic hyperglycaemia [15]. Growth hormone also has multiple effects on glucose kinetics, varying with the duration of exposure and the time interval after exposure. Several investigators have demonstrated that growth hormone has early insulin-like effects [36-38]. However, insulin antagonistic effects of the hormone can be seen 2-12 $\mathrm{h}$ after growth hormone administration [39-41], and could exert a delayed effect on glucose metabolism since even transient elevations of growth hormone have been shown to impair even transient elevations of growth hormone have been shown to impair glucose tolerance for at least $5 \mathrm{~h}$ [41].

Prolonged suppression of endogenous insulin secretion appears to be another factor contributing to insulin resistance after hypoglycaemia. In our experiments in normal subjects, C-peptide levels did not return to baseline until $4 \mathrm{~h}$ after initiation of insulin-induced hypoglycaemia $\left(2 \frac{1}{2} \mathrm{~h}\right.$ after the plasma glucose had returned to clamp levels). Previous studies in dogs have shown that peripheral C-peptide levels reflect portal vein levels with a $30 \mathrm{~min}$ lag phase [42]. In the present study, when the mildly hyperglycaemic clamp was re-established following hypoglycaemia, C-peptide levels failed to rise as quickly as they had when the clamp was initiated prior to hypoglycaemia. Other studies have also shown a delay in stimulated insulin release following insulin-induced hypoglycaemia $[3,9$, 15], which would, of course, enhance the anti-insulin effect of circulating counterregulatory hormones during the initial 2-4 $\mathrm{h}$ after the insulin bolus. However, this mechanism probably does not contribute to glucose intolerance beyond $4 \mathrm{~h}$ in normal subjects when plasma C-peptide levels have returned to normal. The discrepancy between plasma C-peptide and IRI values cannot be readily explained but may be related to a reservoir effect of spare receptors after insulin bolus.

In the studies performed in hypopituitary subjects, both insulin and C-peptide levels were lower than baseline for the entire study period $(7 \mathrm{~h})$ after hypoglycaemia. The persistence of suppressed insulin levels, although not entirely explained, probably accounts for the slightly decreased Rd and dextrose delivery seen in these subjects not exhibiting an increase in hepatic glucose output. A recent study indicating that prior administration of cortisol impairs suppression of insulin secretion by insulin [35] suggests by analogy that the prolonged suppression of insulin levels in the hypopituitary patients might be related to the absence of a cortisol peak.

A recent report suggests that hepatic autoregulation is important in recovery from prolonged severe hypoglycaemia when other neurohormonal mechanisms fail 
to raise the blood glucose to over $2.8 \mathrm{mmol} / 1$ [43]. These authors report that hepatic glucose production did not suppress below $1 \mathrm{mg} \cdot \mathrm{kg}^{-1} \cdot \mathrm{min}^{-1}$ despite very high plasma insulin levels during prolonged hypoglycaemia. We have also found that plasma insulin and blood glucose concentrations which had completely suppressed hepatic glucose production before hypoglycaemia failed to do so for at least $7 \mathrm{~h}$ after hypoglycaemia in normals. The further observation that unsuppressed hepatic glucose output was not observed in the hypopituitary subjects would make autoregulation unlikely in our studies despite the presence of severe hypoglycaemia $(1.7 \mathrm{mmol} / 1)$.

Down-regulation of insulin receptors following the insulin bolus might provide and additional explanation for post-hypoglycaemic insulin resistance. However, in separarate studies we have observed no decrease in erythrocyte insulin receptors following a. single bolus of $0.1 \mathrm{U} / \mathrm{kg}$ of insulin (unpublished observations). Unfortunately, we are unable to assess hepatocyte insulin receptors in order to adequately address this issue. Nevertheless, the lack of insulin resistance following hypoglycaemia in the hypopituitary subjects makes this possibility also less likely.

In conclusion, we have shown that prolonged hypoglycaemic insulin resistance occurs in non-diabetic subjects. The mechanism for this resistance is multifactorial. Our data suggest that elevated counterregulatory hormones coupled with impaired insulin secretion contribute to early insulin resistance, i.e. out to $4 \mathrm{~h}$. Thereafter, in normal man, unsuppressed hepatic glucose production and impaired glucose utilisation lead to persistent insulin resistance for at least $7 \mathrm{~h}$ despite return of insulin and counterregulatory hormone levels to baseline. In the hypopituitary subjects no such rise in hepatic glucose production occurs, suggesting a pituitary factor is responsible in part for the prolonged insulin resistance following hypoglycaemia.

Acknowledgements. We are indebted to H. Kantor and F. Kantor for technical assistance, to M. Carter, R. N., and the staff members of the Clinical Research Center for their assistance. This investigation was supported by Grant RR00065 and AM18903 from the National Institutes of Health and the Juvenile Diabetes Foundation Grant 82 F070. The present study was presented in part at the 22nd Annual Meeting of the European Assiciation for the Study of Diabetes, Rome, Italy, September 16-20, 1986.

\section{References}

1. Somogyi M, Kirstein M (1938) Insulin as a cause of extreme hyperglycaemia and instability. St Louis Medical Society Weekly Bulletin 32: 504

2. Somogyi M (1959) Exacerbation of diabetes by excess insulin action. Am J Med 26: 169-191

3. Frier BM, Corrall RJM, Ashby JP, Baird JD (1980) Attenuation of the pancreatic $B$ cell response to a meal following hypo-glycaemia in man. Diabetologia 18: 297-300

4. Somogyi M (1951) Effect of insulin hypoglycaemia on alimentary hyperglycaemia. J Biol Chem 193: 859-865
5. Oakley NW, Jacobs HS, Turner RC, Williams J, Aquino C Dos S, Nabarro DN (1970) The effect of hypoglycaemia on oral glucose tolerance in normal subjects and patients with pituitary and adrenal disorders. Clin Sci 39: 663-674

6. Gale EAM, Kurtz AB, Tattersall RB (1980) In search of the Somogyi effect. Lancet II: $279-282$

7. Silas JH, Grant DS, Maddocks JL (1981) Transient hemiparetic attacks due to unrecognized nocturnal hypoglycaemia. Br Med J (Clin Res) 282: 132-133

8. Gale EAM, Tattersall RB (1979) Unrecognized nocturnal hypoglycaemia in insulin-treated diabetes. Lancet I: 1049-1052

9. Oleesky S, Shreeve DR, Sutcliffe CH (1974) Brittle diabetes. Quart J Med New Serv XLIII (169): 113-125

10. Shamoon H, Hendler R, Sherwin RS (1980) Altered responsiveness to cortisol, epinephrine and glucagon in insulin-infused juvenile onset diabetes. Diabetes 29: 284-291

11. Felig P (1981) Fuel metabolism. In: Felig P, Baxter JD, Broadus AE, Frohman LR (eds) Endocrinology and metabolism. McGraw-Hill, New York, $p 836$

12. Garber AJ, Cryer PE, Santiago JV, Haymond MW, Pagliara AS, Kipnis DM (1976) The role of adrenergic mechanisms in the substrate and hormonal response to insulin-induced hypo-glycaemia in man. J Clin Invest 58: 7-15

13. Sacca L, Sherwin R, Hendler R, Felig P (1979) Influence of continuous physiologic hyperinsulinemia on glucose kinetics and counterregulatory hormones in normal and diabetic humans. $\mathrm{J}$ Clin Invest 63: 849-857

14. Bolli GB, Gottesman IS, Campbell PJ, Haymond MW, Cryer CE, Gerich JE (1984) Glucose counterregulation and waning of insulin in the Somogyi phenomena (post-hypoglycaemic hyper-glycaemia). N Engl J Med 311: 1214-1219

15. Mintz DH, Finster JL, Taylor AL, Fefer A (1968) The hormonal genesis of glucose intolerance following hypo-glycaemia. Am J Med 45: 187-197

16. McGuire EAH, Helderman JH, Tobin JD, Andres R, Berman M (1976) Effects of arterial versus venous sampling on analysis of glucose kinetics in man. J Appl Physiol 41: 565-573

17. Wall JSR, Steele R, Debodo RC, Altszuler N (1957) Effect of insulin on utilisation and production of circulating glucose. Am J Physiol 189: $43-50$

18. Morgan CR, Lazarow A (1963) Immunoassay of insulin: two antibody system. Diabetes 12: 115-126

19. Kumar MS, Schumacher OP, Deodhar SD (1980) Measurement of serum C-peptide immunoreactivity by radioimmunoassay in insulin-dependent diabetics. Am J Clin Pathol 74: 78-82

20. Schalch DS, Parker ML (1964) A sensitive double antibody immunoassay for human growth hormone in plasma. Nature 203: $1141-1142$

21. Aguilar-Parada E, Eisentraut AM, Unger RH (1969) Pancreatic glucagon secretion in normal and diabetic subjects. Am $\mathbf{J}$ Med Sci 257: 415 419

22. Passon PG, Peuler JD (1973) A simplified radiometric assay for plasma norepinephrine and epinephrine. Anal Biochem 51: L618-631

23. Finegood DT, Vranic M (1985) Possible isotope effect of tritiated glucose tracer during hyperinsulinemic, euglycemic glucose clamps. Diabetes 34: 80A

24. Debodo RC, Steele R, Altszuler N, Dunn A, Bishop JS (1963) On the hormonal regulation of carbohydrate metabolism: studies with C14 glucose. Recent Prog Horm Res 19: 445-488

25. Cowan JS, Hetenyi G (1971) Glucoregulatory responses in normal and diabetic dogs recorded by a new tracer method. Metabolism 20: $360-372$

26. Argoud GM, Schade DS and Eaton RP (1987) Underestimation of hepatic glucose production by radioactive and stable tracers. Am J Physiol 252: E606-E615

27. Gerich J, Cryer P, Rizza R (1980) Hormonal mechanisms in acute glucose counterregulation: the relative roles of glucagon, epinephrine, norepinephrine, growth hormone and cortisol. Metabolism 29 [Suppl]: 1164-1175 
28. Horwitz DL, Rubenstein AH, Reynolds C, Molnar GD, Yamaihara N (1975) Prolonged suppression of insulin release by insulin-induced hypoglycaemia. Horm Metab Res 7: 449-452

29. Verdonk C, Rizza R, Gerich J (1981) Effects of plasm glucose concentration on glucose utilisation and glucose clearance to normal man. Diabetes 30: 535-537

30. Rizza RA, Gerich JE (1979) Persistent effect of sustained hyperglucagonemia on glucose production in man. $J$ Clin Endocrinol Metab 48: 352-355

31. Porte D, Jr (1967) A receptor mechanism for the inhibition of insulin. J Clin Invest 46: 86-94

32. Deibert DC, DeFronzo RA (1980) Epinephrine-induced insulin resistance in man. J Clin Invest 65: 717-721

33. Popp DA, Shah SD, Cryer PE (1982) Role of epinephrine-mediated $\beta$-adrenergic mechanisms in hypoglycaemic glucose counterregulation and post-hypoglycaemic hyperglycaemia in insulindependent diabetes mellitus. J Clin Invest 69: 315-326

34. Shamoon H, Soman V, Sherwin RS (1980) The influence of acute physiological increment of cortisol on fuel metabolism and insulin binding to monocytes in normal humans. J Clin Endocrinol Metab 50: 495-501

35. Clerc D, Wick H, Keller U (1986) Acute cortisol excess results in unimpaired insulin action on lipolysis and branched chain amino acids, but not on glucose kinetics and C-peptide concentrations in man. Metabolism 35: 404 410

36. Adamson U, Cerasi E (1975) Acute suppressive effect of human growth hormone on basal insulin secretion in man. Acta Endocrinol 79: 474-482

37. Adamson U, Wahren J, Cerasi E (1977) Influence of growth hormone on splanchnic glucose production in man. Acta Endocrinol 86: 803-812

38. MacGorman LR, Rizza RA, Gerich JE (1981) Physiological con- centrations of growth hormone exert insulin-like and insulin antagonistic effects on both hepatic and extra-hepatic tissues in man. J Clin Endocrinol Metab 53: 556-559

39. Bratusch-Marrian PR, Smith D, DeFronzo RA (1982) The effect of growth hormone on glucose metabolism and insulin secretion in man. J Clin Endocrinol Metab 55: 973-982

40. Rizza RA, Mandarino LJ, Gerich JE (1982) Effects of growth hormone on insulin action in man: mechanisms of insulin resistance, impaired suppression of glucose production, and impaired stimulation of glucose utilization. Diabetes 31: 663-669

41. Adamson U, Cerasi E (1975) Acute effect of exogenous growth hormone in man: time- and dose-bound modification of glucose tolerance and glucose-induced insulin release. Acta Endocrinol 80: $247-261$

42. Polonsky KS, Pugh W, Jaspan JB, Cohen DM, Karrison T, Tager HS, Rubinstein AH (1984) C-peptide and insulin secretion relationship between peripheral concentrations of $\mathrm{C}$-peptide and insulin and their secretion rates in dogs. $J$ Clin Invest 74 : 1821-1829

43. Bolli G, DeFeo P, Perriello G, DeCosmo S, Ventura M, Campbell P, Brunetti P, Gerich JE (1985) Role of hepatic autoregulation in defense against hypoglycaemia in humans. J Clin Invest 75: $1623-1631$

Received: 1 June 1987

and in revised form: 29 September 1987

Dr. William G. Blackard

Medical College of Virginia

Box 155, MCV Station.

Richmond, VA 23298-0155

USA 